\title{
Enlarging the genetic diversity of winter oilseed rape (WOSR) by crossing with spring oilseed rape (SOSR)
}

\author{
Alice Gourrion ${ }^{1, *}$, Clara Simon ${ }^{2}$, Patrick Vallée ${ }^{1}$, Régine Delourme ${ }^{3}$, Sébastien Chatre ${ }^{1}$ \\ and Jean-Éric Dheu ${ }^{2}$ \\ ${ }^{1}$ RAGT 2n, Druelle, France \\ 2 Limagrain Europe, Verneuil l'Etang, France \\ ${ }^{3}$ UMR IGEPP, INRAE, 35653 Le Rheu, France
}

Received 10 December 2019 - Accepted 11 March 2020

\begin{abstract}
From 1970 to nowadays, breeders have improved oilseed rape (Brassica napus) in many ways: creation of double low varieties (free of erucic acid and with a low content in glucosinolates), increase of the seed yield and quality of seeds and improvement of resistance to diseases. All this work helped oilseed rape to become one of the most produced oilseed crop in the world. However, this intensive breeding on quality has reduced the genetic diversity of winter oilseed rape. In this study, a group of four breeding companies (RAGT, Limagrain, Syngenta, Euralis) called "GIE Colza" has been working with INRAE (National Research Institute for Agriculture, Food and Environment, France) on the FSRSO project "Printiver". This project aimed at enlarging the genetic variability available in winter-type oilseed rape through crossing with spring-type materials to create lines with a winter-type behavior (need of vernalization) and a genetic background that has introgressed spring-type genetic diversity. Two pools have been created and selected for their need of vernalization, date of flowering, yield and other agronomic traits. The Group tested these two pools in multilocal trials. The results show interesting per se value and combining ability.
\end{abstract}

Keywords: oilseed rape / breeding / genetic diversity / combining ability

Résumé - Amélioration de la diversité génétique du colza d'hiver par croisement avec du colza de printemps. De 1970 à nos jours, les sélectionneurs ont amélioré le colza (Brassica napus) sur plusieurs critères: création de variétés double zéro (sans acide érucique et faible teneur en glucosinolates), augmentation du rendement et de la qualité des graines, amélioration de la résistance aux maladies. Ce travail fit du colza l'une des cultures oléagineuses la plus produite dans le monde. Cependant, cette sélection intensive sur des critères de qualité agronomique a diminué la diversité génétique du colza d'hiver. Dans cette étude, un regroupement de quatre entreprises de sélection (RAGT, Limagrain, Syngenta et Euralis) appelé «GIE Colza » a travaillé, en collaboration avec l'Institut national de recherche pour l'agriculture, l'alimentation et l'environnement (INRAE), sur le projet FSRSO «Printiver». Ce projet a pour objectif d'augmenter la variabilité génétique présente chez le colza d'hiver par croisement avec colza de printemps, afin de créer des lignées présentant un comportement de type hiver (besoin de vernalisation) et un fond génétique ayant introgressé de la diversité génétique de colza de printemps. Deux pools génétiques ont été créés et sélectionnés pour leur besoin en vernalisation, date de floraison, rendement et d'autres traits agronomiques. Le GIE Colza a testé ces deux pools dans des essais à plusieurs lieux. Les résultats montrent une bonne valeur per se ainsi qu'une bonne aptitude à la combinaison.

Mots clés : colza / amélioration des plantes / diversité génétique / aptitude à la combinaison

*Correspondence: alice.gourrion@inrae.fr 


\section{Introduction}

Oilseed rape is a global major crop used in human food (oil), animal feed (cattle cake) and chemistry industry. In 2017 , 41 million hectares of oilseed rape produced 89 million tons of seeds in the world (FAOSTAT, 2019), which makes oilseed rape the third most produced oilseed crop after palm and soybean. The main producers are Europe producing wintertype oilseed rape (WOSR), Canada and China producing spring-type oilseed rape (SOSR). The main agronomic difference between WOSR and SOSR relies on the vernalization requirement to induce flowering. Therefore, in Europe, WOSR are sown in late summer/autumn and have early flowering as well as a better yield (35-40 q/ha) compared to SOSR (20-25 q/ha) that are sown in spring and have a shorter biological cycle as well as a late flowering time and therefore a higher risk to encounter drought.

In response to the demand of the market between 1960 and 1990, breeders reduced the erucic acid and glucosinolate content in oilseed rape seeds, creating varieties called double zero « $00 »$. Due to this intensive breeding, genetic diversity of winter oilseed rape has been considerably narrowed (double bottlenecks) (Friedt and Snowdon, 2010). Therefore, current elite WOSR has a low genetic diversity, which may be a limitation to genetic progress.

The main varietal type used by breeders for OSR breeding is F1 hybrids. As OSR is mainly autogamous, the F1 hybrid seed production was possible based on the discovery and development of cytoplasmic or genic male sterility systems (Pinochet and Renard, 2012). The performance of a hybrid relative to the performance of the parents is called "heterosis". It means the enhanced vigor, seed yield or quality of the hybrid due to the combination of two parent lines. In theory, the more genetically distant the parents are, the more effective this heterosis effect can be (Falconer and Mackay, 1996). However this theory has been disproved for the case of oilseed rape in a study which showed that there is no correlation between genetic diversity and heterosis, but between the general combining ability (GCA) and heterosis (Tian et al., 2016). Either way, the choice of the parents is crucial for the development of enhanced hybrid. Having a large genetic diversity enables us to increase the possibilities of crosses and thus the possibilities of results.

To this extent, knowing the reduced genetic diversity within the elite WOSR varieties, some experiments were made to bring new sources of diversity, for example by creating resynthesized oilseed rape (by crossing $B$. oleracea with B. rapa) (Girke et al., 2012). Hasan et al. (2006) created a core collection and genetically characterized 96 accessions using 30 mapped SSR primer combinations, underlining the high genetic divergence between WOSR and SOSR and concluding with its use to improve heterotis. In another study, winter genetic diversity was introduced into spring genetic background (Butruille et al., 1999a, b), which showed that the average yield of the experimental hybrids was higher in each tested environment than the yield of spring-by-spring experimental hybrids. Following this study results, more research were done on the QTL involved in the increased yield of WOSR and its effect when introgressed into canola (spring-type), showing that some QTL involved in increased seed yield is linked to QTLs involved in high glucosinolate content (Quijada et al., 2006).
For its part, the French "GIE Colza" gathering four breeding companies (RAGT2n, Limagrain, Syngenta, Euralis) and INRAE (National Research Institute for Agriculture, Food and Environment, France) set up a project in order to improve WOSR performance by enlarging genetic diversity of winter oilseed rape by crossing elite WOSR with SOSR.

\section{Objectives}

The first objective of this project was to enlarge the genetic variability of WOSR through the production of two populations and derived lines with different introgression levels of SOSR diversity. The value of the derived lines was assessed by estimating their general and specific combining ability. On a long term, it should enable the breeding of new parental lines useable by breeders to improve the yield potential and the quality of the commercial hybrids.

The second objective was the development of molecular markers linked to the winter/spring type of the material and the vernalization requirement. These would help further breeding through a quicker and easier screening of only one type (in our case, winter-type) of oilseed rape.

On a six year-long project, two pools of materials (P1 and P2), composed by a blend of WOSR and SOSR having in theory respectively $75 \%$ and $87.5 \%$ of SOSR in their genetic background, have been created. Different elite WOSR malesterile lines were crossed with maintainer and backcrossed to restorer SOSR lines from diverse geographic origin. The P1 population was obtained after two generations of intercrossing and lines were derived through self-pollinations. The P2 population was obtained with the same scheme but with an additional backcross to restorer SOSR materials before intercrossing. Spring-type plants and lines were identified when flowering after sowing in spring (i.e. without vernalization) and they were discarded. The derived materials were observed and selected in diverse environments in France. The progenies were fixed for the $R f o$ restorer gene and confirmed to be winter-type OSR. Yield of the lines (per se value) and of derived F1 hybrids was estimated as well as seed quality assessed by NIRS (Near Infrared Spectroscopy).

The genetic diversity of the $\mathrm{P} 1$ and $\mathrm{P} 2$ derived lines was assessed by SNP markers and compared to WOSR and SOSR varieties. Then the yield and oil content were studied and compared to elite WOSR controls.

\section{Results}

The principal component analysis (PCA) showed a clear distinction between WOSR elites and SOSR elites. P1 and P2 are in the same cluster and are intermediate between SOSR and WOSR varieties (Fig. 1). However, we observe that the P2 population seems closer to the non-European spring-type material than the P1 population, which was consistent with its origin.

Each fixed progeny has been crossed to 3 or 4 WOSR elite male-sterile testers to test their combining ability; the tests of the hybrids were held in four different locations in France.

In Figure 2a, for each control, a hybrid is represented as four points corresponding to the four locations.

Many hybrids derived from P1 and P2 populations showed yield and oil results equivalent or superior to the commercial 


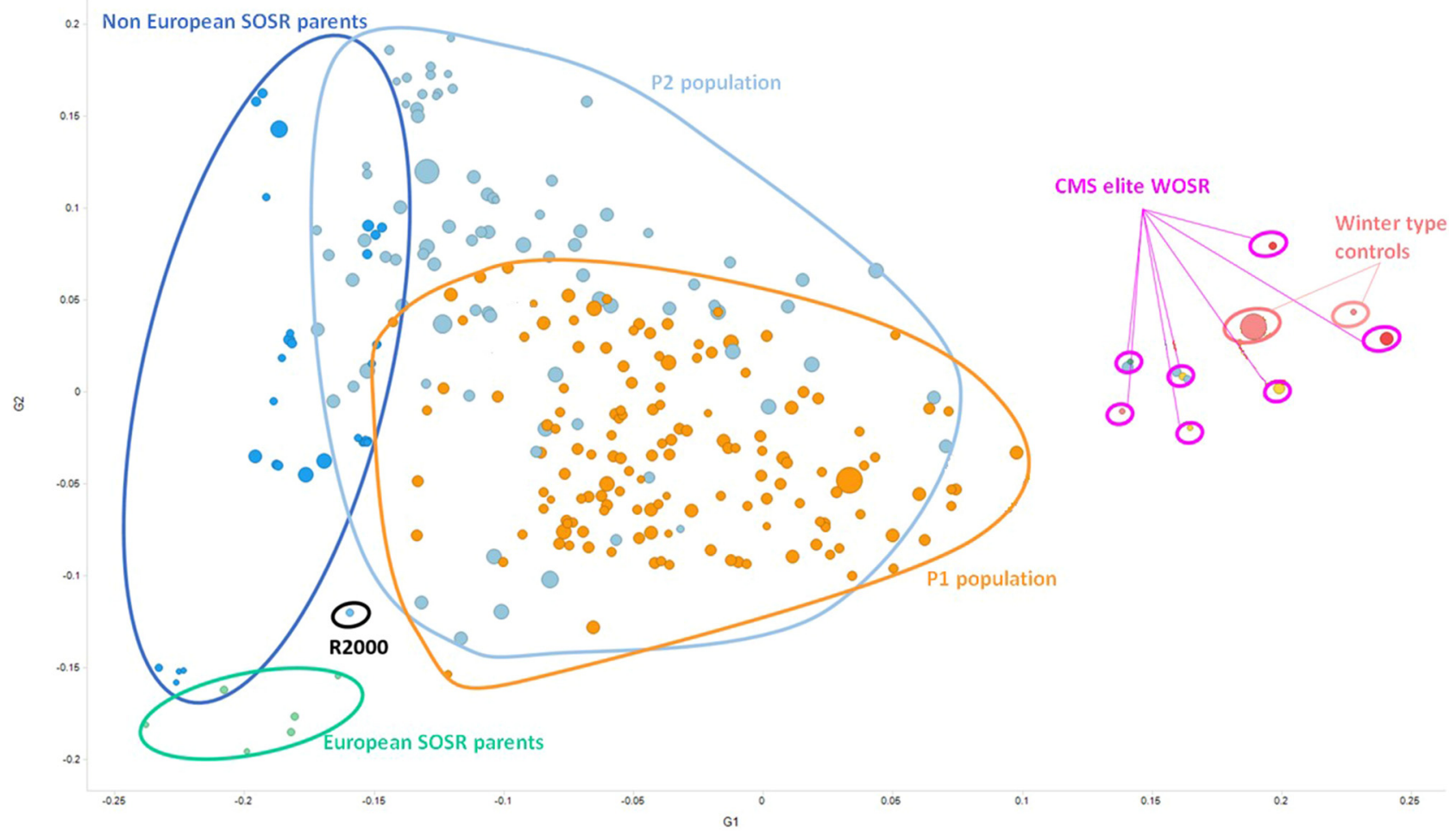

Fig. 1. PCA showing the structuration of lines derived from P1 and P2 populations, SOSR and WOSR parental lines and WOSR controls. R2000 is the SOSR restorer line used in the crosses.

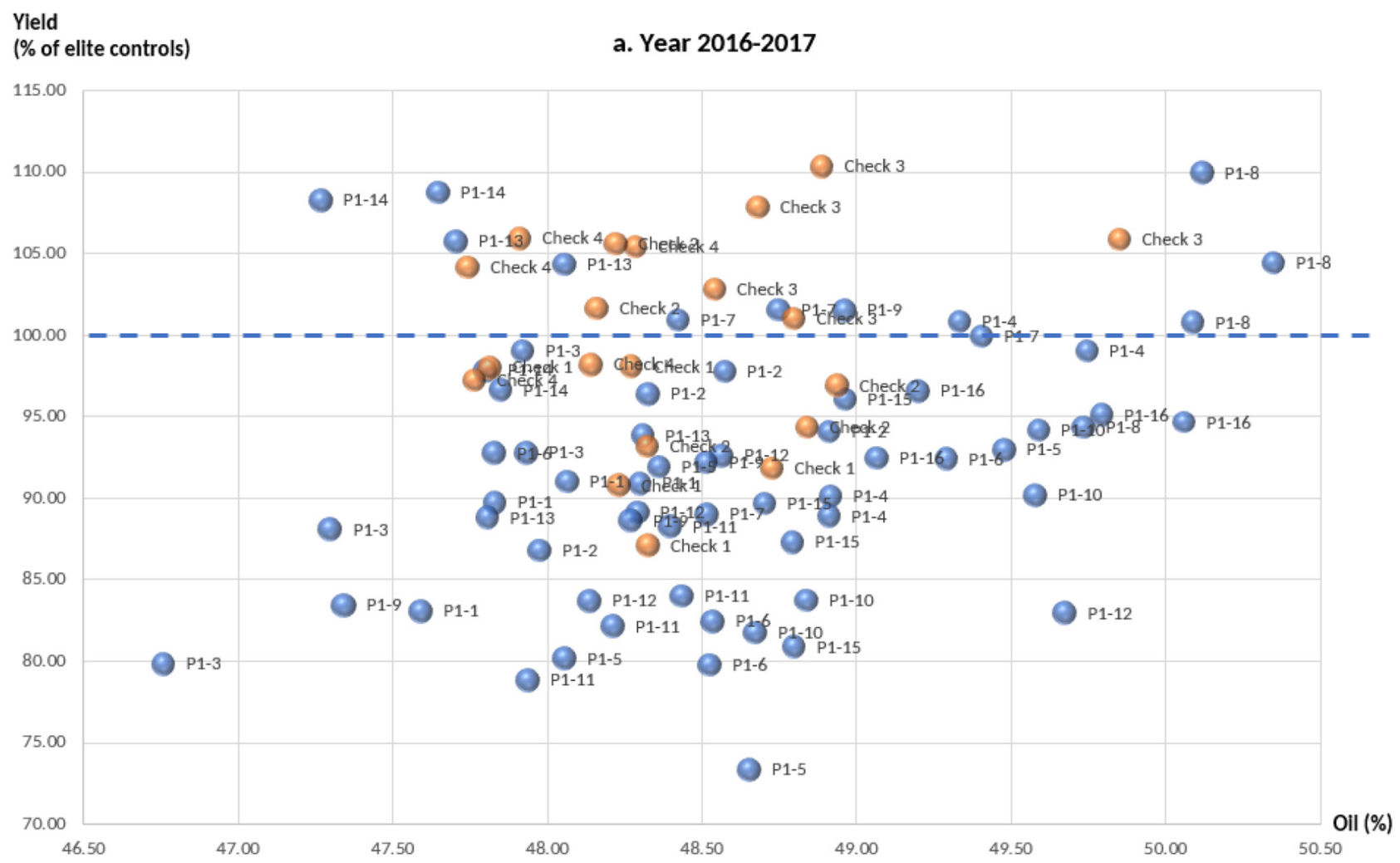

Fig. 2. 


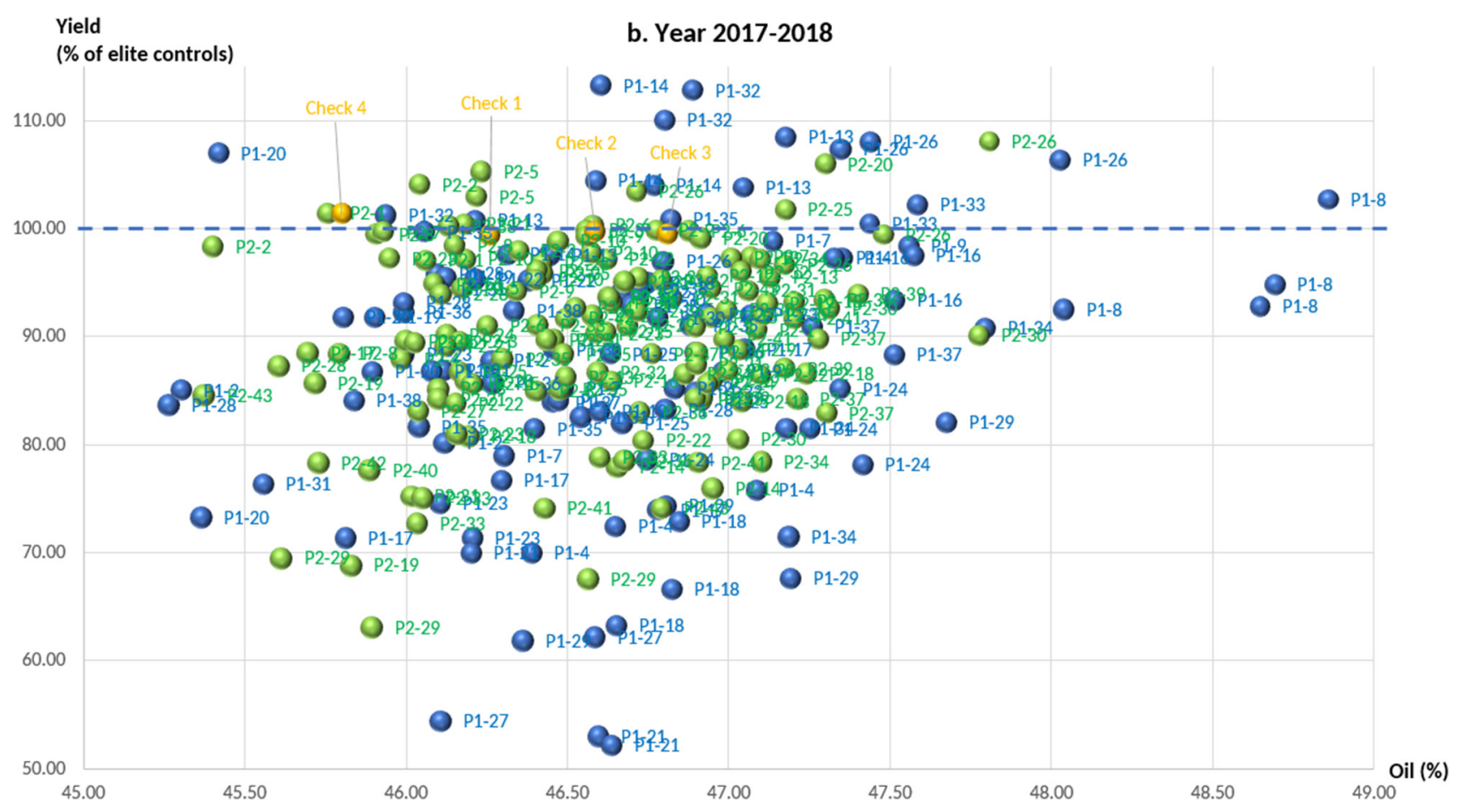

Fig. 2. Yield of the genotypes in percentage of controls (y) in function of their oil content in percentage (x). a: Orange points are elite WOSR controls, blue points are hybrids derived from P1 tested in 2016-2017; b: Yellow points are elite WOSR controls, green points are hybrids derived from P2, blue points are hybrids derived from P1 tested in 2017-2018.

hybrids used as checks (Fig. 2). Furthermore, the results of some lines from 2017-2018 corroborated the results of 20162017 (for example P1-8, P1-13 and P1-14).

Anova showed for both years significant differences between the genotypes for oil content and seed yield. The Newman-Keuls test enabled us to create groups of genotypes with significantly different means. Regarding the P1 population, in 2016-2017, all the genotypes showed an equal seed yield to the controls and 4 genotypes had equal or higher oil content compared to the controls. The P1-8 genotype showed a significantly higher oil content compared to the controls ( $50.1 \%$ for P1-8 and $48.9 \%$ for the best check), and its yield was not significantly different from the best controls $(102.4 \%$ and $105.6 \%$ of the control mean for P1-8 and check 3, respectively). P1-16 seems to also have an interesting behavior with an oil content and seed yield not significantly different from the best controls. These two genotypes showed the same results in 2017-2018. The P2 population is more homogeneous, as no genotype showed significantly different seed yield from the controls, and only two genotypes showed lower oil content compared to the controls.

\section{Discussion and conclusion}

This project demonstrated the relevance of enlarging the genetic diversity of the elite WOSR germplasm through intercrossing with diverse SOSR lines. The results showed that it was possible to breed for winter habit OSR without losing too much of the spring genetic background. It confirmed that crossing spring type OSR with winter type OSR is an interesting source of variability and strengthen the interest for spring germplasm to improve heterosis of winter oilseed rape.
As the first tests in combination showed promising performance considering the relatively low effort made on agronomic selection in these populations and their progenies, this project gives new leads of genetic sources for identifying good combining performance and improving innovativeness in oilseed rape breeding in the future.

In keeping with this project, recombinant lines were derived through single seed descent applied to $\mathrm{P} 1$ population in order to develop markers for vernalization requirement and earliness. The derived association population showed a large variability for the date of flowering as well as for the need of vernalization, which enabled to carry out a GWAS (Genome Wide Association Study) and the identification of QTL involved in vernalization requirement as well as some QTL explaining flowering earliness. The markers linked to QTL of vernalization are promising tools that will facilitate the selection of interesting progenies out of the initial populations and will be used for further experiments and screenings. The continuation of the project will focus on the validation of the vernalization markers on another set of lines as well as the improvement of the prediction accuracy of the flowering time markers.

Acknowledgments. The authors would like to acknowledge the GIE Colza and all its contributors: Philippe Fouillard from RAGT 2n, Laurent Hanneton from Limagrain Europe, Thomas Foubert and Marie Boillot from Euralis Semences, Julien Moreau, Virginie Mirleau-Thébaud and Christopher Sauvage from Syngenta, as well as the rest of their teams, for carrying out the multi-local trials. We would also like to thank Michel Renard (UMR IGEPP INRA) who initiated the project, Claude Domin (UMR IGEPP INRA) who contributed to the material 
production and the INRAE Experimental Unit (UE La Motte, Le Rheu) for field experimentations.

The authors acknowledge the financial support of the FASO (Sofiproteol) under the Printiver project.

\section{References}

Butruille DV, Guries RP, Osborn TC. 1999a. Increasing yield of spring oilseed rape hybrids (Brassica napus L.) through introgression of winter germplasm. Crop Sci 39: 1491-1496.

Butruille DV, Guries RP, Osborn TC. 1999b. Linkage analysis of molecular markers and quantitative trait loci in populations of inbred backcross lines of Brassica napus L. Genetics 153: 949-964.

Falconer DS, Mackay TFC. 1996. Introduction to quantitative genetics, 4th ed. Harlow, Essex, UK: Longmans Green.

FAOSTAT. http://www.fao.org/faostat/fr/\#data/QC.

Friedt W, Snowdon R. 2010. Oilseed rape. In : Vollmann J, Rajcan I, eds. Oil Crops Handbook of Plant Breeding, vol. 4. New York, NY: Springer, pp. 91-126.
Girke A, Schierholt A, Becker HC. 2012. Extending the rapeseed gene pool with resynthesized Brassica napus II: Heterosis. Theor Appl Genet 124(6): 1017-1026. https://doi.org/10.1007/ s00122-011-1765-7.

Hasan M, Seyis F, Badani AG, et al. 2006. Analysis of genetic diversity in the Brassica napus L. gene pool using SSR Markers. Genet Resour Crop Evolut 53(4): 793-802. https://doi.org/ 10.1007/s10722-004-5541-2.

Pinochet X, Renard M. 2012. Progrès génétique en colza et perspectives. Oléagineux, Corps gras, Lipides (OCL) 19(3). http://dx.doi.org/10.1051/ocl.2012.0456.

Quijada PA, Udall JA, Lambert B, Osborn TC. 2006. Quantitative trait analysis of seed yield and other complex traits in hybrid spring rapeseed (Brassica napus L.): 1. Identification of genomic regions from winter germplasm. Theor Appl Genet. Theoretische Und Angewandte Genetik 113(3): 549-61. https://doi.org/ 10.1007/s00122-006-0323-1.

Tian HY, Siraj AC, Sheng WH. 2016. Relationships between genetic distance, combining ability and heterosis in rapeseed (Brassica napus L.). Euphytica 213(1): 1. https://doi.org/10.1007/ s10681-016-1788-x.

Cite this article as: Gourrion A, Simon C, Vallée P, Delourme R, Chatre S, Dheu J-E. 2020. Enlarging the genetic diversity of winter oilseed rape (WOSR) by crossing with spring oilseed rape (SOSR). OCL 27: 16. 